\title{
DETERMINAÇÃO DO TEMPO DE VIDA DE PRATELEIRA DE IOGURTE COM DE POLPA DE FRUTA POR MEIO DA POPULAÇÃO DE BACTÉRIAS LÁTICAS TOTAIS
}

\section{DETERMINATION OF THE TIME OF THE YOGURT WITH FRUIT PULP SHELF LIFE BY THE TOTAL LACTIC BACTERIA POPULATION}

\begin{abstract}
Denise Milléo Almeida ${ }^{1}$; Rosilene Aparecida Prestes²; Maria Carolina Oliveira Ribeiro ${ }^{3}$ Giovana de Arruda Moura Pietrowski ${ }^{4}$

1,2,3,4Universidade Tecnológica Federal do Paraná - UTFPR - Ponta Grossa - Brasil milleo@utfpr.edu.br
\end{abstract}

\section{Resumo}

A estimativa do tempo de vida de prateleira de um produto depende basicamente da qualidade inicial da matéria prima, do processamento e da forma de armazenamento. O objetivo deste trabalho foi determinar o tempo de vida de prateleira de iogurtes com polpa de fruta, considerando como fator limitante a população de bactérias láticas totais. A contagem destas bactérias foi realizada em cinco marcas de iogurte com polpa de fruta, sabor morango, durante 44 dias. Foram consideradas as temperaturas de $7^{\circ} \mathrm{C}, 3^{\circ} \mathrm{C}, 15^{\circ} \mathrm{C}$ e $11^{\circ} \mathrm{C}$ como condições de processamento, estocagem, distribuição e comercialização, respectivamente. O limite para determinar a vida útil do produto, nas temperaturas estudadas, foi a população mínima de $10^{7}$ UFC.g ${ }^{-1}$ de bactérias láticas totais. As amostras de iogurtes apresentaram como tempo de vida de prateleira médio de 33,5 dias, indicando que os produtos não apresentaram população de bactérias láticas viáveis durante o período médio estabelecido pelos fabricantes de 40 dias, promovendo perda nas características de identidade e qualidade do iogurte.

Palavras-chave: processament; estocagem; distribuição; comercialização; iogurte.

\section{Introdução}

O Ministério da Agricultura, Pecuária e Abastecimento (MAPA) oficializa pela Resolução $\mathrm{n}^{\circ} 5$ de 13 novembro de 2000 os padrões de identidade e requisitos mínimos de qualidade para leites fermentados comercializados no Brasil (BRASIL, 2001). Esta legislação define que leites fermentados são produtos resultantes da fermentação de leite pasteurizado ou esterilizado, por fermentos láticos próprios. Para o iogurte, deve ser utilizada uma associação das culturas de Streptococcus salivarius subsp. thermophilus e Lactobacillus delbrueckii subsp. bulgaricus, podendo ser acompanhadas por outras bactérias láticas como Lactobacillus acidophilus ou cultivos 
do gênero Bifidobacterium. Estes microrganismos devem permanecer viáveis, ativos e abundantes no produto final, ou seja, a contagem total de bactérias ácido láticas (BAL) não poderá ser inferior a $10^{7}$ UFC. $\mathrm{g}^{-1}$ de produto durante seu prazo de validade.

De acordo com a International Dairy Federation, países como a França e Espanha estabelecem a concentração de $10^{5}$ UFC. $\mathrm{mL}^{-1}$ como o mínimo de bactérias láticas viáveis durante o período de vida de prateleira de iogurte. Outros países estabelecem valores de $10^{6} \mathrm{UFC} / \mathrm{mL}$ (Suíça e Itália), $10^{7}$ UFC.mL ${ }^{-1}$ (Japão) e $10^{8}$ UFC.mL ${ }^{-1}$ (Portugal). O Mercosul estabelece um limite mínimo

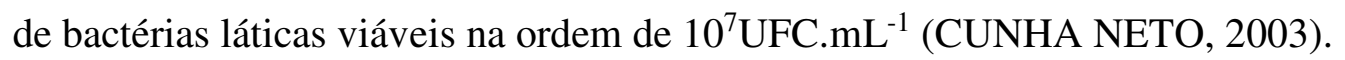

As culturas láticas utilizam o leite como nicho ecológico e existe uma relação simbiótica entre dois microrganismos, na qual cada um deles estimula a multiplicação do outro. Os Lactobacillus bulgaricus liberam aminoácidos e peptídeos das proteínas do leite, o que possibilita a multiplicação de Streptococcus thermophilus nos primeiros estágios da fermentação. O Streptococcus themophilus, por sua vez, produz ácido fórmico, o qual estimula a multiplicação de Lactobacillus bulgaricus, diminuindo o tempo de fermentação e conferindo ao produto características peculiares (MARAFON, 2010). Estudos têm mostrado que bactérias do iogurte (Streptococcus thermophilus e Lactobacillus bulgaricus) sobrevivem bem no produto durante a vida de prateleira (SILVA, 2007).

De acordo com Perez et al. (2007) os efeitos benéficos das bactérias láticas estão ligados ao aumento da digestibilidade, aumento do valor nutritivo, níveis elevados das vitaminas do complexo B e de alguns aminoácidos, melhor utilização da lactose, níveis reduzidos de lactose no produto e maior disponibilidade de lactase, comparando o leite in natura com o iogurte.

Para Reis et al. (2011) a ação destas culturas também promove alteração de odor e sabor apreciável, bem como, a adição de frutas no produto final tem influenciado no aumento do consumo e na popularização, devido à melhoria no sabor, aparência e constituição nutricional. Segundo Damin et al., (2006) os iogurtes devem apresentar os atributos como corpo que deve ser viscoso, firme e coeso; a textura deve ser suave, livre de grumos e sem fissuras; deve ter sabor ácido e o maior componente volátil deve ser o acetaldeído.

De acordo com Sivieri e Oliveira (2002), do ponto de vista de vida de prateleira, a qualidade dos alimentos é definida por parâmetros fisiológicos, valores nutricionais e atributos sensoriais como cor, sabor e textura ou consistência. A diminuição da qualidade e a redução da vida de prateleira podem ser conseqüência do efeito de uma ou mais destas propriedades.

Para obter um produto de alta qualidade durante sua vida de prateleira, são indispensáveis algumas condições de processamento, fatores como higiene rigorosa, controle de contaminações cruzadas, qualidade dos ingredientes utilizados, cuidados no envase, estocagem e distribuição devem fazer parte da rotina da fábrica (SANTOS, 2002). Sendo monitorados e controlados os 
parâmetros de processo, pode-se determinar o final do tempo de vida de prateleira, ou seja, o momento em que o produto não é próprio para o consumo (SIVIERI e OLIVEIRA, 2002).

Considerando estes aspectos o objetivo deste trabalho foi determinar a vida de prateleira de iogurte com polpa de fruta, utilizando como fator limitante a população de bactérias láticas totais.

\section{Materiais e Métodos}

\subsection{Condições experimentais}

Foram utilizadas cinco marcas comerciais de iogurte, adicionado de polpa de fruta sabor morango, adquirida no comércio local de Ponta Grossa - Paraná.

Para determinar a vida de prateleira, os produtos foram submetidos ao armazenamento simulando as temperaturas próximas das condições de processamento, estocagem, distribuição e comercialização, ou seja, a $7,3,15$ e $11^{\circ} \mathrm{C}$, respectivamente, durante 44 dias.

\subsection{Determinação do tempo de vida de prateleira}

O tempo de vida de prateleira das amostras foi estimado utilizando metodologia para testes acelerados segundo o proposto por Moura e Germer (2004). O fator estabelecido como limitante para a avaliação foi o número total de bactérias láticas que, segundo os Padrões de Identidade e Qualidade (PIQ) para leites fermentados, deve ter um mínimo de $10^{7} \mathrm{UFC}_{\mathrm{g}}{ }^{-1}$ de iogurte.

O tempo, em dias, necessário para que nas condições simuladas de armazenamento o fator limitante alcance seu limite mínimo é denominado de vida útil (VU).

A taxa de deterioração diária (TD) relaciona a capacidade de perda da característica estudada para cada dia de armazenamento nas condições simuladas, como descreve a equação 1.

$$
T D_{\text {diâria }}=\frac{1}{V v}(\text { Eq. } 1)
$$

Onde,

VU (vida útil) - tempo necessário para atingir limite mínimo do fator limitante, obtido em gráfico.

O tempo de vida de prateleira do produto foi estabelecido considerando a influência de fatores globais de deterioração inerentes as etapas de processamento, estocagem, distribuição e comercialização. Portanto as equações 2, 3, 4 e 5 descrevem a forma de cálculo dos fatores globais de deterioração para cada etapa e a equação 6 demonstra o cálculo para o tempo de vida de prateleira do produto analisado. 


$$
\begin{aligned}
& \text { Processamento }=1 \times \mathrm{TD} D_{\text {processamento }} \text { (Eq. 2) } \\
& \text { Estocagem }=\frac{V U_{\text {estaragem }}}{\text { ttotalarmarenamenta }} \times T D_{\text {estocagem }} \text { (Eq. 3) }
\end{aligned}
$$

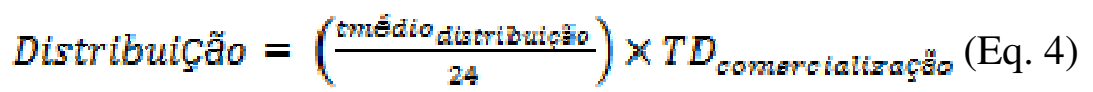

$$
\begin{aligned}
& \text { Comercialização }=1-(\text { Processamento }+ \text { Estocagem }+ \text { Distribuị̧ăo) (Eq. 5) }
\end{aligned}
$$

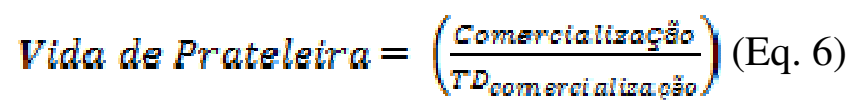

Onde,

TD processamento - taxa de deterioração diária na temperatura de processamento $\left(\mathrm{dia}^{-1}\right)$

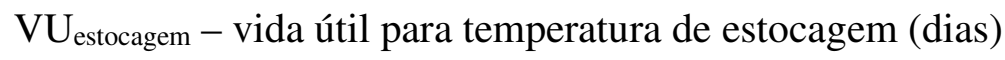

TD estocagem - taxa de deterioração diária na temperatura de estocagem $\left(\operatorname{dia}^{-1}\right)$

$\mathrm{t}$ total armazenamento - tempo total de armazenamento do ensaio (dias)

t médio distribuição - tempo médio de distribuição durante um dia (horas)

TD distribuição - Taxa de deterioração diária na temperatura de distribuição ( dia $^{-1}$ )

TD comercialização - taxa de deterioração diária na temperatura de comercialização $\left(\operatorname{dia}^{-1}\right)$

\subsection{Contagem de bactérias ácido láticas totais}

Durante os dias $1^{\circ}, 9^{\circ}, 16^{\circ}, 23^{\circ}, 30^{\circ}, 37^{\circ}$ e $44^{\circ}$ do armazenamento simulado, foram realizadas contagens de bactérias láticas totais em meio DE MAN, ROGOSA, SHARPE (MRS) pelo método pour plate a $37^{\circ} \mathrm{C}$ em anaerobiose (SILVA et al. 2010), em triplicata.

\subsection{Análise dos Dados}

As médias, obtidas para vida de prateleira entre as marcas analisadas, foram comparadas

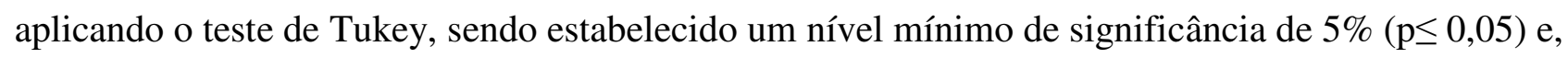
o programa utilizado foi o SASM - Agri (CANTERI et al. 2001).

\section{Resultados e Discussão}

\subsection{Contagem de bactérias láticas totais}


A contagem inicial de bactérias láticas nos iogurtes foram de $3,7 \times 10^{8}$ a $5,2 \times 10^{9} \mathrm{UFC}_{\mathrm{C}} \mathrm{g}^{-1}$, entre as marcas analisadas, portanto, apresentando valor acima do estabelecido pela legislação, Resolução n 5 de 13 de novembro de 2000, cujo padrão é $10^{7}$ UFC.g ${ }^{-1}$ (Tabela 1).

As marcas $\mathrm{A}, \mathrm{C}$ e $\mathrm{D}$ nas temperaturas de $7^{\circ} \mathrm{C}$ e $3^{\circ} \mathrm{C}$ a população de células apresentou diminuição em 16 dias de armazenamento, e as marcas B e E a redução foi em 23 dias, e nas condições de $15^{\circ} \mathrm{C}$ e $11^{\circ} \mathrm{C}$ a redução foi observada com 9 dias de avaliação em todas as marcas. Resultados foram próximos aos encontrados por Figueiredo et al. (2004), que verificaram números estáveis de cepas láticas quando armazenadas sob refrigeração a $6^{\circ} \mathrm{C}$ e $8^{\circ} \mathrm{C}$ ao longo de 14 dias, e a cultura armazenada em temperaturas de $10^{\circ} \mathrm{C}$ e $12^{\circ} \mathrm{C}$ se manteve estável até o $6^{\circ}$ dia, com posterior diminuição de um ciclo logarítmico após 14 dias de armazenamento.

De acordo com Perez et al. (2007), em iogurtes recém produzidos o número de microrganismos apresenta em torno de $10^{9} \mathrm{UFC}_{\mathrm{g}}{ }^{-1}$, embora este valor dependa do fabricante, devendo ter no mínimo $10^{7} \mathrm{UFC}^{-1}{ }^{-1}$. No entanto, durante o seu armazenamento, esse número pode reduzir para $10^{6} \mathrm{UFC} . \mathrm{g}^{-1} \mathrm{e}$, no caso, de iogurte mantido a $5^{\circ} \mathrm{C}$ por mais de 60 dias, o número de bastonetes apresenta diminuição maior em relação ao número de cocos. Damin et al. (2006) avaliaram quatro marcas de iogurtes comerciais armazenadas nas temperaturas de $5^{\circ} \mathrm{C}$ e $20^{\circ} \mathrm{C}$ por 7 dias, e observaram um número inferior de Lactobacillus bulgaricus ao número de Streptococcus thermophilus tendo a população total inferior do exigido pela legislação brasileira vigente.

Para os resultados obtidos durante o armazenamento na temperatura de $15^{\circ} \mathrm{C}$, houve uma redução de quatro ciclos logarítmicos aos 44 dias de armazenamento na maioria das marcas, com exceção da marca E. Enquanto que para as condições de processamento, estocagem e distribuição durante o mesmo período a redução foi de três ciclos logarítmicos. Beal et al. (1999) evidenciaram em amostras de iogurte que a concentração bacteriana foi influenciada pelo tempo de estocagem, pH final da fermentação, associação das linhagens e temperatura de incubação, decaindo de $40 \%$ a $75 \%$ em períodos de 7 a 21 dias de armazenamento refrigerado. 
Tabela 1. Contagem de bactérias láticas totais em amostras de iogurtes

\begin{tabular}{|c|c|c|c|c|c|}
\hline \multirow{2}{*}{$\begin{array}{l}\text { Marca de } \\
\text { iogurte }\end{array}$} & \multirow{2}{*}{$\begin{array}{c}\text { Tempo } \\
\text { (dias) }\end{array}$} & \multicolumn{4}{|c|}{ Bactérias Láticas Totais (UFC.g g $\left.^{-1}\right)$} \\
\hline & & $3^{\circ} \mathrm{C}$ & $7^{\circ} \mathrm{C}$ & $11^{\circ} \mathrm{C}$ & $15^{\circ} \mathrm{C}$ \\
\hline \multirow{7}{*}{ A } & 1 & $5,0 \times 10^{9}$ & $5,0 \times 10^{9}$ & $5,0 \times 10^{9}$ & $5,0 \times 10^{9}$ \\
\hline & 9 & $2,0 \times 10^{9}$ & $1,0 \times 10^{9}$ & $5,0 \times 10^{8}$ & $3,0 \times 10^{8}$ \\
\hline & 16 & $4,0 \times 10^{8}$ & $6,0 \times 10^{8}$ & $3,0 \times 10^{8}$ & $1,0 \times 10^{8}$ \\
\hline & 23 & $3,0 \times 10^{8}$ & $2,3 \times 10^{8}$ & $1,0 \times 10^{8}$ & $1,0 \times 10^{6 *}$ \\
\hline & 30 & $3,0 \times 10^{8}$ & $2,1 \times 10^{8}$ & $1,0 \times 10^{8}$ & $3,0 \times 10^{5^{*}}$ \\
\hline & 37 & $2,8 \times 10^{7}$ & $2,5 \times 10^{7}$ & $1,0 \times 10^{7}$ & $2,3 \times 10^{5^{*}}$ \\
\hline & 44 & $1,5 \times 10^{6 *}$ & $1,0 \times 10^{6 *}$ & $2,8 \times 10^{6 *}$ & $2,0 \times 10^{5 *}$ \\
\hline \multirow{7}{*}{$\mathrm{B}$} & 1 & $3,7 \times 10^{8}$ & $3,7 \times 10^{8}$ & $3,7 \times 10^{8}$ & $3,7 \times 10^{8}$ \\
\hline & 9 & $2,1 \times 10^{8}$ & $1,5 \times 10^{8}$ & $8,0 \times 10^{7}$ & $3,0 \times 10^{7}$ \\
\hline & 16 & $1,9 \times 10^{8}$ & $1,7 \times 10^{8}$ & $8,1 \times 10^{7}$ & $2,6 \times 10^{7}$ \\
\hline & 23 & $2,9 \times 10^{7}$ & $1,3 \times 10^{8}$ & $1,4 \times 10^{7}$ & $7,0 \times 10^{6^{*}}$ \\
\hline & 30 & $3,0 \times 10^{7}$ & $1,1 \times 10^{7}$ & $1,0 \times 10^{6^{*}}$ & $2,7 \times 10^{5^{*}}$ \\
\hline & 37 & $2,3 \times 10^{7}$ & $2,1 \times 10^{7}$ & $2,7 \times 10^{6^{*}}$ & $2,5 \times 10^{5^{*}}$ \\
\hline & 44 & $1,1 \times 10^{6^{*}}$ & $1,4 \times 10^{6 *}$ & $2,1 \times 10^{6 *}$ & $2,2 \times 10^{5^{*}}$ \\
\hline \multirow{7}{*}{$\mathrm{C}$} & 1 & $4,7 \times 10^{9}$ & $4,7 \times 10^{9}$ & $4,7 \times 10^{9}$ & $4,7 \times 10^{9}$ \\
\hline & 9 & $4,1 \times 10^{9}$ & $4,0 \times 10^{9}$ & $6,9 \times 10^{8}$ & $8,7 \times 10^{8}$ \\
\hline & 16 & $4,0 \times 10^{8}$ & $6,0 \times 10^{8}$ & $3,0 \times 10^{8}$ & $1,0 \times 10^{8}$ \\
\hline & 23 & $3,8 \times 10^{8}$ & $4,3 \times 10^{8}$ & $2,6 \times 10^{8}$ & $5,0 \times 10^{6^{*}}$ \\
\hline & 30 & $3,3 \times 10^{8}$ & $3,1 \times 10^{8}$ & $5,0 \times 10^{7}$ & $2,8 \times 10^{5^{*}}$ \\
\hline & 37 & $2,8 \times 10^{8}$ & $2,3 \times 10^{7}$ & $8,6 \times 10^{6 *}$ & $1.0 \times 10^{5^{*}}$ \\
\hline & 44 & $1,9 \times 10^{6^{*}}$ & $1,5 \times 10^{6^{*}}$ & $5,8 \times 10^{6 *}$ & $1,1 \times 10^{5^{*}}$ \\
\hline \multirow{7}{*}{$\mathrm{D}$} & 1 & $5,2 \times 10^{9}$ & $5,2 \times 10^{9}$ & $5,2 \times 10^{9}$ & $5,2 \times 10^{9}$ \\
\hline & 9 & $5,0 \times 10^{9}$ & $5,1 \times 10^{9}$ & $4,9 \times 10^{8}$ & $4,8 \times 10^{8}$ \\
\hline & 16 & $6,8 \times 10^{8}$ & $7,4 \times 10^{8}$ & $3,9 \times 10^{8}$ & $3,3 \times 10^{8}$ \\
\hline & 23 & $5,0 \times 10^{8}$ & $5,3 \times 10^{8}$ & $2,0 \times 10^{7}$ & $2,0 \times 10^{6^{*}}$ \\
\hline & 30 & $2,4 \times 10^{8}$ & $2,1 \times 10^{8}$ & $1,8 \times 10^{7}$ & $7,1 \times 10^{5^{*}}$ \\
\hline & 37 & $2,8 \times 10^{7}$ & $4,9 \times 10^{7}$ & $1,0 \times 10^{7}$ & $2,0 \times 10^{5^{*}}$ \\
\hline & 44 & $4,9 \times 10^{6 *}$ & $1,7 \times 10^{6^{*}}$ & $3,0 \times 10^{6^{*}}$ & $1,0 \times 10^{5^{*}}$ \\
\hline \multirow{7}{*}{$\mathrm{E}$} & 1 & $4,9 \times 10^{9}$ & $4,9 \times 10^{9}$ & $4,9 \times 10^{9}$ & $4,9 \times 10^{9}$ \\
\hline & 9 & $1,7 \times 10^{9}$ & $3,0 \times 10^{9}$ & $3,3 \times 10^{8}$ & $3,8 \times 10^{8}$ \\
\hline & 16 & $4,3 \times 10^{9}$ & $5,1 \times 10^{9}$ & $3,0 \times 10^{8}$ & $1,6 \times 10^{8}$ \\
\hline & 23 & $3,0 \times 10^{8}$ & $2,0 \times 10^{8}$ & $1,1 \times 10^{8}$ & $1,0 \times 10^{7}$ \\
\hline & 30 & $5,1 \times 10^{8}$ & $2,1 \times 10^{7}$ & $1,0 \times 10^{8}$ & $3,0 \times 10^{6^{*}}$ \\
\hline & 37 & $4,8 \times 10^{7}$ & $2,0 \times 10^{7}$ & $1,0 \times 10^{7}$ & $2,1 \times 10^{5^{*}}$ \\
\hline & 44 & $5,0 \times 10^{6^{*}}$ & $1,8 \times 10^{6^{*}}$ & $4,8 \times 10^{6 *}$ & $2,0 \times 10^{5^{*}}$ \\
\hline
\end{tabular}

NOTA: * Abaixo do limite da vida de prateleira. 


\subsection{Determinação do tempo de vida de prateleira}

A Figura 1 apresenta o gráfico construído com o objetivo de estabelecer a vida útil do produto nas condições de armazenamento que simulam as etapas de processamento, estocagem, distribuição e comercialização.

Figura 1 - População de bactérias láticas em função do tempo de armazenamento em cinco marcas de iogurtes (A, B. C, $\mathrm{D}$ e E).

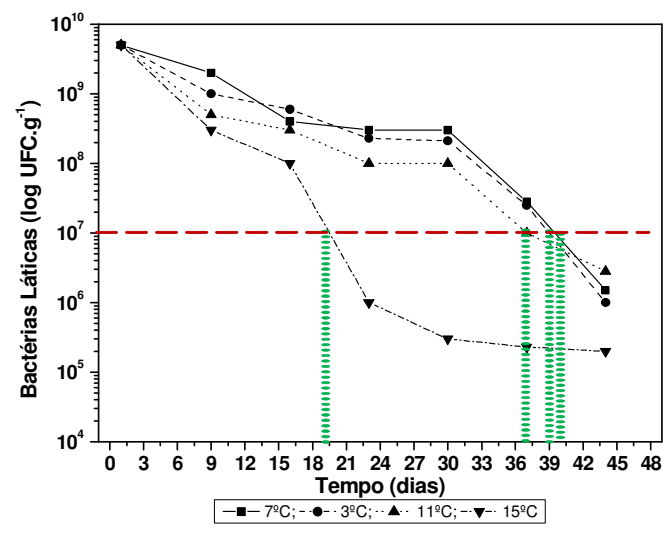

(A)

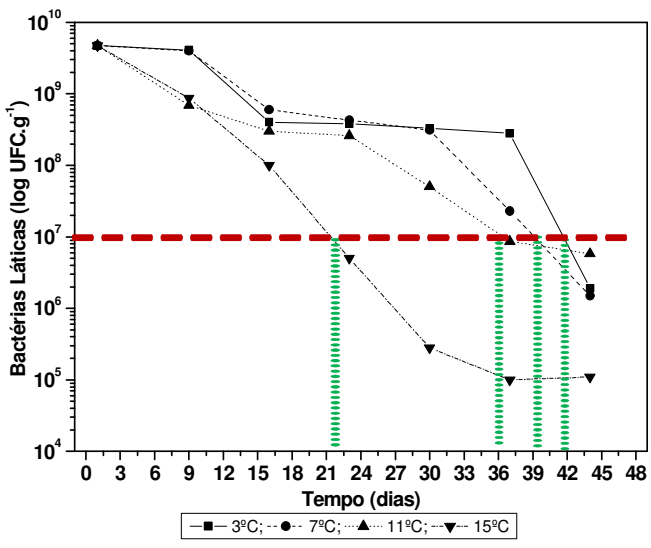

(C)

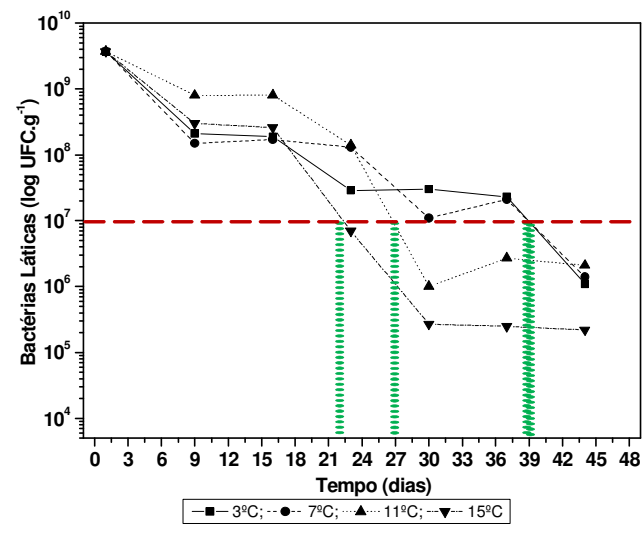

(B)

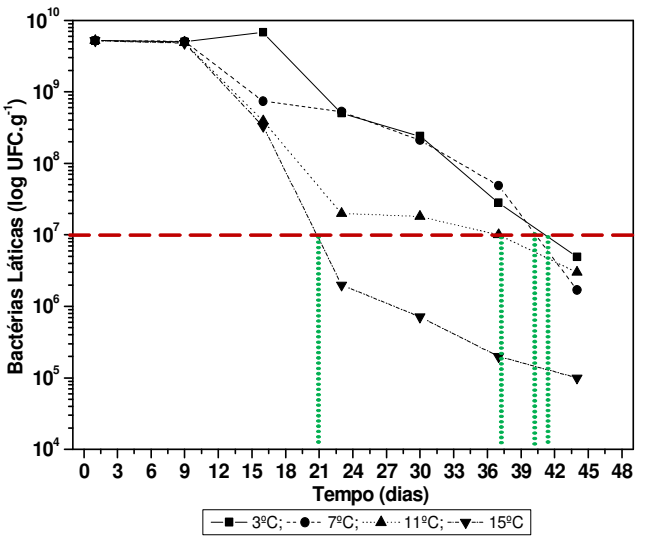

(D)

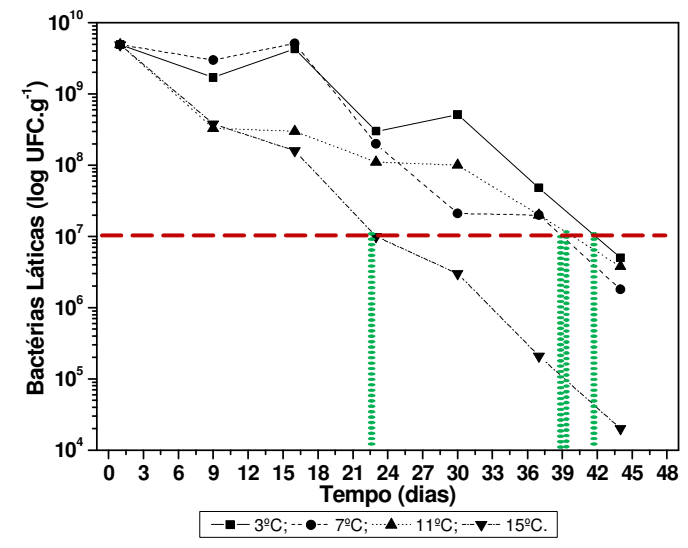

(E) 
A Tabela 2 apresenta os dados obtidos para vida útil e taxa de deterioração diária para a amostra de iogurte considerando a população definida pela legislação.

Tabela 2 - Taxa de deterioração diária e vida útil de iogurte nas condições avaliadas.

\begin{tabular}{|c|c|c|c|c|}
\hline Marcas de Iogurtes & Processos & Temperatura $\left({ }^{\circ} \mathrm{C}\right)$ & $\begin{array}{l}\text { Vida Útil } \\
\text { (dias) }\end{array}$ & $\begin{array}{c}\text { Taxa de Deterioração Diária } \\
\left(\operatorname{dias}^{-1}\right)\end{array}$ \\
\hline \multirow{4}{*}{ A } & Processamento & $\overline{7}$ & 39 & 0,0256 \\
\hline & Estocagem & 3 & 41 & 0,0243 \\
\hline & Distribuição & 15 & 19 & 0,0526 \\
\hline & Comercialização & 11 & 37 & 0,0270 \\
\hline \multirow{4}{*}{ B } & Processamento & 7 & 39 & 0,0256 \\
\hline & Estocagem & 3 & 39 & 0,0256 \\
\hline & Distribuição & 15 & 22,5 & 0,0444 \\
\hline & Comercialização & 11 & 27 & 0,0370 \\
\hline \multirow{4}{*}{$\mathrm{C}$} & Processamento & 7 & 40 & 0,0250 \\
\hline & Estocagem & 3 & 42 & 0,0238 \\
\hline & Distribuição & 15 & 22 & 0,0454 \\
\hline & Comercialização & 11 & 36 & 0,0277 \\
\hline \multirow{4}{*}{$\mathrm{D}$} & Processamento & 7 & 40 & 0,0250 \\
\hline & Estocagem & 3 & 42 & 0,0238 \\
\hline & Distribuição & 15 & 21 & 0,0476 \\
\hline & Comercialização & 11 & 37 & 0,0270 \\
\hline \multirow{4}{*}{$\mathrm{E}$} & Processamento & 7 & 39 & 0,0256 \\
\hline & Estocagem & 3 & 42 & 0,0238 \\
\hline & Distribuição & 15 & 22,5 & 0,0444 \\
\hline & Comercialização & 11 & 39 & 0,0256 \\
\hline
\end{tabular}

De acordo com os valores obtidos na Tabela 2, foram calculados os fatores globais de deterioração referente a cada etapa proposta: processamento, estocagem, distribuição e comercialização, utilizando o formulário descrito anteriormente. Os resultados estão demonstrados na Tabela 3, assim como o tempo de vida de prateleira calculado. Para o fator global de deterioração da etapa de distribuição, foi considerado como tempo médio para distribuição o período de duas horas.

Portanto, considerando as temperaturas em que foram submetidos os iogurtes, durante o processamento, estocagem, distribuição e comercialização, o tempo de vida de prateleira médio entre as marcas analisadas foi de 33,5 dias, sendo menor que o estabelecido pelos fabricantes, em torno de 40 dias. Isso mostra que os produtos não apresentaram concentração de bactérias láticas viáveis durante seu período de comercialização, ocasionando perda na qualidade quanto ao aspecto funcional. Há necessidade que os fabricantes adotem maior rigor no controle de qualidade do seu processo tecnológico, incluindo monitoração das características do inóculo, estendendo de forma periódica e aleatória, aos estabelecimentos de comercialização. 
Tabela 3 - Fatores globais de deterioração e vida de prateleira calculada.

\begin{tabular}{|c|c|c|c|}
\hline Marcas de Iogurtes & Etapas & $\begin{array}{l}\text { Fator Global de Deterioração } \\
\qquad\left(\operatorname{dias}^{-1}\right)\end{array}$ & $\begin{array}{l}\text { Vida de Prateleira } \\
\text { (dias) }\end{array}$ \\
\hline \multirow{4}{*}{ A } & Processamento & 0,0256 & \multirow{4}{*}{$35,1^{\mathrm{a}} \pm 1,0$} \\
\hline & Estocagem & 0,0226 & \\
\hline & Distribuição & 0,0044 & \\
\hline & Comercialização & 0,9474 & \\
\hline \multirow{4}{*}{ B } & Processamento & 0,0256 & \multirow{4}{*}{$25,6^{\mathrm{b}} \pm 0,99$} \\
\hline & Estocagem & 0,0256 & \\
\hline & Distribuição & 0,0444 & \\
\hline & Comercialização & 0,0370 & \\
\hline \multirow{4}{*}{$\mathrm{C}$} & Processamento & 0,0250 & \multirow{4}{*}{$34,4^{\mathrm{a}} \pm 0,95$} \\
\hline & Estocagem & 0,0238 & \\
\hline & Distribuição & 0,0454 & \\
\hline & Comercialização & 0,0277 & \\
\hline \multirow{4}{*}{$\mathrm{D}$} & Processamento & 0,0250 & \multirow{4}{*}{$35,2^{\mathrm{a}} \pm 0,97$} \\
\hline & Estocagem & 0,0238 & \\
\hline & Distribuição & 0,0476 & \\
\hline & Comercialização & 0,0270 & \\
\hline \multirow{4}{*}{$\mathrm{E}$} & Processamento & 0,0256 & \multirow{4}{*}{$37^{\mathrm{a}}, 1 \pm 1,0$} \\
\hline & Estocagem & 0,0238 & \\
\hline & Distribuição & 0,0444 & \\
\hline & Comercialização & 0,0256 & \\
\hline
\end{tabular}

Nota: Os valores com letras minúsculas iguais nas colunas não diferem pelo teste de Tukey (p $\leq 0,05)$, em nível de $95 \%$ confiança.

De acordo com Damin et al. (2006) o tempo de prateleira de iogurte, deve ser em torno de 30 dias, mantendo as características próprias para consumo. O tempo de vida de prateleira calculado, quando comparado ao tempo médio informado pelos fabricantes (40 dias), apresentou uma redução de aproximadamente de sete dias. Esta variação pode ser decorrente das condições de temperatura estabelecidas pelo fabricante no momento da determinação da vida de prateleira do produto avaliado. Porém, a redução da população de bactérias láticas totais ao longo do período de comercialização também pode estar relacionada com problemas tecnológicos no processo de fabricação, assim como na manutenção inadequada da cadeia do frio desde a etapa de estocagem, ainda na indústria, até a comercialização, nos pontos de venda.

Para Zacarchengo e Roig (2004), a redução da vida de prateleira do iogurte pode ser resultante das condições de processamento, como higiene, contaminações cruzadas, qualidade dos ingredientes, cuidados no envase, estocagem e distribuição. Segundo Santos (2002), Téo et al. (2003) a falta de controle da temperatura, o descuido com a conservação dos equipamentos de refrigeração, e muitas vezes o desligamento desses equipamentos durante a noite, são fatos que irão prejudicar o produto durante seu armazenamento interferindo na sua qualidade nutricional, físicoquímica e na vida de prateleira.

A temperatura inadequada de armazenagem dos produtos refrigerados é responsável por mais da metade dos produtos que deterioram nas gôndolas dos supermercados. O grau de calor 
impróprio interfere no crescimento bacteriano e, no caso dos derivados lácteos, o papel do frio na cadeia do leite é de fundamental importância, durante o processamento, armazenamento, distribuição e o ponto de venda. Alguns graus a mais levam a um comprometimento da segurança sanitária dos produtos e da vida-de-prateleira (CARVALHO, 2007).

\title{
4. CONCLUSÃO
}

De acordo com os resultados obtidos, o tempo de vida de prateleira média estabelecida para as marcas analisadas de iogurtes foram de 33,5 dias, sendo aproximadamente sete dias menor do que o proposto pelos fabricantes.

\begin{abstract}
The estimate time of a product shelf life depends, basically, on the initial quality of the raw material, processing and storage form. The purpose of this paper was determinate the time of the shelf life of the yogurt with fruit pulp, considering as limiting factor the total population of lactic bacteria. The count of these bacteria was made in five brands of yogurt with fruit pulp, strawberry flavor, during 44 days. It was considered the temperatures of $7^{\circ} \mathrm{C}, 3^{\circ} \mathrm{C}, 15^{\circ} \mathrm{C}$, and $11^{\circ} \mathrm{C}$ as conditions of processing, storage, distribution and commercialization, respectively. The limit to determinate the useful life of the product, in the study temperatures, was the minimum population of $10^{7}$ UFC. $g^{-1}$ of total lactic bacteria. The yogurt samples showed as medium shelf life time of 33,5 days, indicating that the products do not showed viable lactic bacteria population during the medium period established by the manufacturers, of 40 days, leading to loss of identity and yogurt quality characteristics.
\end{abstract}

Key-words: processing, storage, distribution, marketing, yogurt.

\section{Referências}

BEAL, C; SKOKANOVA, J.; LATRILLE, E. ; MARTIN, N.; CORRIEU, G. Combined effects of culture conditions and storage time on acidification and viscosity of stirred yogurt. Journal Dairy Science, v.82, n.4, p.673-681, 1999. Disponível em:<http://dx.doi.org/10.3168/jds.S0022-0302(99)75283-5,> Acesso em: 2 jun. 2013.

BRASIL. Ministério da Agricultura, Pecuária e Abastecimento. Departamento de Inspeção de Produtos de origem Animal. Resolução $n^{\circ}$ 5, de 13 de novembro de 2000. Estabelece o Regulamento Técnico de Identidade e Qualidade de Leites Fermentados. Diário Oficial da União, Brasília, 27 de novembro de 2000, seção I, republicada 02 de janeiro de 2001.

CANTERI, M. G., Althaus, R. A., VIRGEns FIlHO, J. S., GiGlioti, E. A., GODOY, C. V. SASM - Agri: Sistema para análise e separação de médias em experimentos agrícolas pelos métodos Scoft - Knott, Tukey e Duncan. Revista Brasileira de Agrocomputação, v.1, n.2, p.18-24. 2001. Disponível em:< http://www.agrocomputacao.deinfo.uepg.br> Acesso em: 20 mai. 2013.

CARVALHO, I. Clientes ignoram risco de má refrigeração. Disponível em: http://www.tribunademinas.com.br/especiais/reportagens. Acesso em: 8 de abril de 2007.

CUNHA NETO, O.C. Avaliação do iogurte natural produzido com leite de búfala contendo diferentes níveis de gordura. 2003. 58 f. Dissertação (Mestrado em Zootecnia) - Faculdade de Zootecnia e Engenharia de Alimentos, Universidade de São Paulo. 
DAMIN, M. R.; ALMEIDA, K.E.; MINOWA, E.; OLIVEIRA, M. N. Propriedades físico-químicas e viabilidade de Streptococcus salivarius subsp. thermophilus e Lactobacillus delbrueckii sbsp. bulgaricus em diferentes marcas de iogurtes comerciais no período final da vida de prateleira. Revista Leite e Derivados, São Paulo, v. 15, n. 94, p. 20-30, 2006.

FIGUEIREDO, H. M.; PASSOS, F. J. V.; MORAES, C. A.; PASSOS, F. M. L. TEIXEIRA, M. A. Produção de leite não-fermentado contendo Lactobacillus acidophilus UFV H2b20 isolado no Brasil. Brazilian Journal of Food Technology, v.7, n.2, p.139-144, 2004.

MARAFON, A.P. Otimização das propriedades reológicas e sensoriais de iogurtes probióticos enriquecidos com proteínas lácteas. 2010. 84 f. Dissertação (Mestrado em Tecnologia Bioquímico-Farmacêutica) - Faculdade de Ciências Farmacêuticas, Universidade de São Paulo.

MOURA, S. C. S. R. de; GERMER, S. P. M. Reações de transformações e vida de prateleira de alimentos processados: manual técnico $\mathrm{n}^{\circ}$ 6. 3.ed. Campinas: Instituto de Tecnologia de Alimentos, 2004.

PEREZ, K.J.; GUARIENTI, C.; COSTA, J.A.V.; COLLA, L.M. Viabilidade de bactérias láticas em iogurte adicionado de biomassa da microalga Spirulina platensis durante o armazenamento refrigerado. Alimentos e Nutrição, v.18, n.1, p.77-82, 2007.

REIS, S. de M.; PINTO, M.S.; BRANDI, I.V. Efeito do teor de sólidos não gordurosos e da concentração de sacarose na acidificação de iogurte por bactérias láticas. Revista do Instituto de Laticínios Cândido Tostes, v.66, n.378, p.34-39, 2011.

SANTOS, J. A. Tendências de iogurtes: ingredientes que dão um diferencial ao produto. Revista Leite e Derivados, v.1, n. 63 , p. 48-53, 2002.

SILVA, N.; JUNQUEIRA, V.C.A.; SILVEIRA, N.F.A. Manual de métodos de análise microbiológica de alimentos. São Paulo, Varella, 295 p., 2010.

SILVA, S. V. Desenvolvimento de iogurte probiótico com prebiótico. 2007. 106 f. Dissertação (Mestrado em Ciência e Tecnologia dos Alimentos) - Centro de Ciências Rurais, Universidade de Santa Maria.

SIVIERI, K.; OLIVEIRA, M. N. Avaliação da vida de prateleira de bebidas lácteas preparadas com fat replacers. Ciência e Tecnologia de Alimentos, v. 22, n. 1, p.24-31, 2002.

TÉO, C. R. P. A.; COELHO, S. R. M.; COELHO, L. M. Concentração de bactérias láticas em leites fermentados acidófilos comercializados em Toledo - PR. Revista Nutrição Brasil, n. 3, p. 8-13, 2003.

ZACARCHENGO, P. B.; ROIG, S. M. Avaliação sensorial, microbiológica e de pós-acidificação durante a vida de prateleira de leites fermentados contendo Streptococcus thermophilus, Bifidobacterium longum e Lactobacillus acidophilus. Ciência e Tecnologia de Alimentos, v. 24, n. 4, p. 13-19, 2004. 